\title{
Entry, Stay or Exit: A Dynamic Model of Route Arrangements under Code-Share Alliances in the U.S. Airline Industry
}

\author{
Angela Yan Du \\ Assistant Professor of Economics \\ Department of Economics, Finance and Accounting \\ Robbins College of Business and Entrepreneurship \\ Fort Hays State University \\ Hays, KS 67601 \\ USA
}

\begin{abstract}
Code-sharing is one of the most important and popular alliances in the U.S. airline industry since 1990s. Under code-sharing, partner firms merge their computerized reservation systems and benefit from their expanded networks and schedule frequency without operating additional aircraft, gaining exposure in markets where they do not operate directly but participate via display of their flight numbers. As a result, airlines are able to generate greater passenger volumes, resulting in the lower marginal operating cost. Even though previous studies have extensively examined code-share alliances either empirically or theoretically, no paper has so far theoretically addressed the code-share route arrangements dynamically under the airline network framework. To fill this gap, this paper develops a dynamic game theoretical model to investigate the strategic decisions of flight route arrangements under code-share network partnership. We derive three Nash equilibria: first, when airline carriers decide to enter a code-share partnership; second, after entering into code-share agreement, when carriers decide any specific route to continue to stay code-shared; and third, when carriers decide any specific route to exit from code-sharing.
\end{abstract}

JEL Classification: L93 L13 D43 D81

Keywords: Airline Alliances Code-sharing Entry Stay Exit

\section{Introduction}

Code-sharing has emerged as one of the most important forms of alliance in the airline industry since the middle of 1990s. Under code-sharing, contracting firms merge their computerized reservation systems so that each contracting carrier can issue tickets with their own flight numbers on flights operated by other contracting air carriers. Through code-sharing, partner firms effectively link their networks without operating additional aircraft and gain exposure in markets where they do not operate directly but participate via display of their flight numbers. As a result, airlines are able to make use of hub-and-spoke systems to generate greater passenger volumes. Due to economies of traffic density, the marginal operating cost of carrying an additional passenger drops with increased volume, explaining why code-sharing has become a popular form of airline alliance.

The first major code-sharing alliance in the US airline industry began in the middle of the 1990s between Continental and America West Airlines. The America West and Continental code-sharing arrangement lasted 8 years, from 1994 to 2002. During the code-sharing period, individual routes were added and old routes dropped. Indeed, the route structure of the code-share agreement was very dynamic as indicated in Table 3.1. Of all the routes that were code-shared, only 6 routes remained in the agreement for almost the entire 1998 - 2002 period. There were 1219 routes that were in the agreement for one quarter and then were dropped (See Table 3.2). Different decisions in these code-shared route arrangements reflect different operating strategies in response to route market structure and entry-deterring actions taken by incumbent firms. The purpose of this paper is to develop a dynamic game theoretical model to investigate the strategic decisions of flight route arrangements under code-share network partnership. 
Previous studies have extensively examined the effect of code-sharing on air fares, passenger volumes, operating costs and consumer welfare (Oum, Park and Zhang (1996), Park (1997), Park and Zhang (2000), Park, Zhang and Zhang (2001), Park, Park and Zhang (2003), Brueckner and Whalen (2000), Brueckner (2001, 2003), Hassin and Shy (2004), Bamberger, Carlton and Neumann (2004), Armantier and Richard (2005a, 2005b), Chua, Kew and Yong (2005), Gayle (2006), Ito and Lee (2007) and Du, McMullen and Kerkvliet (2008). Ito and Lee (2005, 2007) have suggested that it may be important to distinguish between traditional code-sharing and virtual codesharing. Whereas traditional code-sharing typically refers to combining the networks of two distinct operating carriers, virtual code-sharing involves a single operating carrier and a marketing carrier that differs from the operating carrier. Ito and Lee (2005) argue that the majority of the U.S. domestic code-sharing fit the definition of virtual code-sharing.

To provide more information on the motivation for entering traditional code-share arrangements on individual routes and why the route arrangement keeps changing dynamically under a network structure, this paper extends the study by McMullen and Du (2012) in which the determinants of route level participation in the America West and Continental code-share agreement were examined and the study by Du and McMullen (2015) who further explain the distinction made between traditional and virtually code-shared routes and find that the decision to enter into code-sharing on a route is significantly different for virtual and traditional code-shared routes. Overall, these findings imply that virtual code-sharing tends to take place in less dense markets which may not support many carriers or flights, in contrast to traditional code-sharing, which is undertaken to achieve the networking economics and cost savings derived from dense markets. These results support Ito and Lee's (2005, 2007) argument that virtual code-sharing is used by alliance firms as a generic or qualitatively inferior product to further segment customers between those who are willing to purchase the branded premium product (pure on-line ticket) and those who are not. The aim of the paper is to derive a game theory model to investigate the code-sharing arrangements (traditional) in the airline industry under different market conditions. Even though previous study has been extensively either theoretically or empirically focused on the traditional or parallel code-sharing, few research has been addressing code-sharing under a network structural model except that Bilotkach (2007) found that semi-complementary partnerships yield a higher welfare without consideration of network effect. Furthermore, little study has investigated the impact under different demand and cost specifications and assumptions of strategic interaction between firms. Specifically, in the paper, as economies of traffic density and price elasticity of demand vary during the business cycles, the strategic decisions of traditional code-sharing could differ as market conditions change, which is exactly what happened in the Continental and America West Alliances.

\section{Theoretical Model}

\subsection{Before Code-sharing}

Following Sinclair (1993), we assume that a monopolist airline operates a hub-and-spoke system which consists of the hub city $H$ and other $\mathrm{N}$ spoke cities, $i=1,2, \ldots, \mathrm{N}$. So the air travel demand between any spoke city $i$ and the hub city $H$ (including travel demand from both $\mathrm{H}$ to $i$ and $i$ to $\mathrm{H}$ ) is given by $q_{H i}=a_{H i}-b_{H i} P_{H i}, \quad i=1, \ldots N$

and the air travel demand between any two spoke cities $i$ and $j(j \neq i)$ including the travel from $i$ to $j$ and from $j$ to $i$ through the hub city $H$ is given by $q_{i j}=a_{i j}-b_{i j} P_{i j}, \quad i=1, \ldots N ; j=1, \ldots N ; j \neq i$

Let $c_{H i}$ be the marginal cost of servicing a passenger between $i$ and $\mathrm{H}$ and $c_{i j}$ be the marginal cost of servicing a passenger between $i$ and $j$ through $H$ where $c_{i j}$ is the sum of the marginal costs on the two segments $c_{H i}$ and $c_{H j}$, i.e.; $c_{i j}=c_{i H}+c_{H j}$. For example, before code-sharing, one code sharer --- firm 1 operates a monopoly hub-andspoke flight system with $\mathrm{H}$ as its hub and $\mathrm{A}, \mathrm{B}, \mathrm{C}$ and $\mathrm{D}$ as its spoke cities. We also assume that the cost savings from offering indirect hub delivery such as flights A-H-B are greater than the loss of revenue from forgoing the more lucrative direct service A-B, so the firm will prefer to provide flight service A-H-B rather than A-B. ${ }^{1}$

Then firm 1's profits before code-sharing from operating this hub-and-spoke system are written as:

\footnotetext{
${ }^{1}$ Please see Sinclair (1993) for the equilibrium conditions of adopting a hub-and-spoke system rather than a direct flight service. 


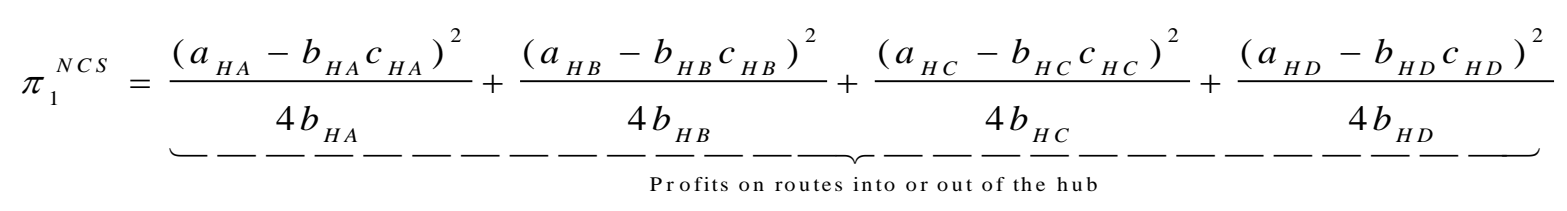

$$
\begin{aligned}
& +\frac{\left(a_{A B}-b_{A B}\left(c_{A H}+c_{H B}\right)\right)^{2}}{4 b_{A B}}+\frac{\left(a_{A C}-b_{A C}\left(c_{A H}+c_{H C}\right)\right)^{2}}{4 b_{A C}}+\frac{\left(a_{A D}-b_{A D}\left(c_{A H}+c_{H D}\right)\right)^{2}}{4 b_{A D}} \\
& +\frac{\left(a_{B C}-b_{B C}\left(c_{B H}+c_{H C}\right)\right)^{2}}{4 b_{B C}}+\frac{\left(a_{B D}-b_{B D}\left(c_{B H}+c_{H D}\right)\right)^{2}}{4 b_{B D}}+\frac{\left(a_{C D}-b_{C D}\left(c_{C H}+c_{H D}\right)\right)^{2}}{4 b_{C D}} \\
& -----------\frac{{ }^{B} C}{\text { Profits on spoke routes }}------\frac{{ }^{B D}}{-}-----
\end{aligned}
$$

Similarly, the other code-sharer---firm 2 also operates a monopoly hub-and-spoke system with $H^{\prime}$ as its hub and $A^{\prime}, B^{\prime}, C^{\prime}$ and $D^{\prime}$ as its spoke cities. Besides, the market incumbent --- firm 3 operates its own monopoly huband-spoke system with $H^{\prime \prime}$ as its hub and $A^{\prime \prime}, B ", C$ " and $D$ " as its spoke cities.

\subsection{After Code-sharing}

Under code-sharing, firm 1 (firm 2) chooses several spoke cities in its own hub-and-spoke system as the connecting airport cities and constitutes the complementary code-shared routes with firm 2 (firm 1). We limit our attention to one-stop (two segments) complementary code-shared flights only, so there are actually three airport cities involved the origin airport, the connecting airport and the destination airport. Every airport acts as either the hub or the spoke city in the code-sharing. If we assume alliance firms are symmetric, then there are totally eight ways of setting up code-sharing Hub-Hub-Hub, Hub-Hub-Spoke, Hub-Spoke-Hub, Hub-Spoke-Spoke, SpokeHub-Hub, Spoke-Hub-Spoke, Spoke-Spoke-Hub and Spoke-Spoke-Spoke. If a city is the hub city for one firm but a spoke city for another firm, we regard this city as a hub city. For example, H-C-H' and H-D-H' are two "HubSpoke-Hub" kind of code-shared routes. To keep the model as succinct as possible without losing any generality, the theoretical model and profit function specified in the paper is based on Hub-Spoke-Hub code-sharing route arrangement. However, the profit function from other code-sharing route arrangements can be specified similarly without changing the essence of equilibrium conditions derived from the paper. Please refer to Figure A1 for details. In Figure 2.2, both city $C\left(C^{\prime}\right)$ and $D\left(D^{\prime}\right)$ are the spoke cities in firm 1 and 2's hub-and-spoke systems respectively. Before code-sharing, neither of the firms provides services on the trip with city $H$ as the origin and city $H^{\prime}$ as the destination but the market incumbent---firm 3 provides one-stop flights $A$ "' $(H)$ - $H^{\prime \prime}-B^{\prime \prime}\left(H^{\prime}\right)$ through its own hub $H^{\prime \prime}$ and enjoys the monopoly profits. Under code-sharing, alliance firms choose their spoke cities such as $C\left(C^{\prime}\right)$ and $D\left(D^{\prime}\right)$ as the connecting airport cities and provide code-shared flights $H$ - $C$ - $H^{\prime}$ and (or) $H-D-H^{\prime}$ on the trip with city $H$ as the origin and city $H^{\prime}$ as the destination. Therefore, through code- sharing, firm 1 and firm 2, acting as one firm, enter route $H H^{\prime}$ and compete with the one-stop flights offered by the market incumbent---firm 3. Due to economies of traffic density, the increased passenger volumes from code-shared flights will decrease the marginal operating cost on segments $H C\left(H^{\prime} C^{\prime}\right)$ and $H D\left(H^{\prime} D^{\prime}\right)$ in both firm 1 and firm 2's hub-and-spoke system, assuming all other things stay the same. Let $\underline{c}_{H i}$ be the marginal cost on the segment $H i$ after code-sharing where $\underline{c}_{H i}$ satisfies $\underline{c}_{H i}<c_{H i}$--- the marginal cost on the segment $H i$ before code-sharing. The decrease in marginal costs on the segments $H C$ and $H D$ also helps decrease the marginal cost of flight itineraries that contain either of the two segments such as $A-H-C, B-H-C, A-H-D, B-H-D$ and $C-H-D$. For example, the marginal cost of flights on route $A-H-D$ after code-sharing, denoted by $\underline{c}_{A D}\left(\underline{c}_{A D}=c_{A H}+\underline{c}_{H D}\right)$, satisfies $\underline{c}_{A D}<c_{A D}$---the marginal cost on route $A-H-D$ before code-sharing $\left(c_{A D}=c_{A H}+c_{H D}\right)$ because $\underline{c}_{H D}<c_{H D}$. Accordingly, the marginal operating cost of firm 2 will decrease by the same way as well.

However, the marginal cost of the market incumbent (firm 3) on segment $H H^{\prime \prime}$ and $H$ ' $H$ ' will increase because some passengers may choose code-shared flights offered by firm 1 (or firm 2) instead of one-stop flights offered by firm 3. Decreased passenger volumes of firm 3 on the segments $H H^{\prime \prime}\left(A{ }^{\prime \prime} H\right.$ ") and $H$ " $H$ ' ( $H$ "' $B$ ") will increase the marginal cost on these segments and on the flight itineraries that contain either of these segments. 
Let $\bar{c}_{H_{H}}\left(\bar{c}_{H H^{\prime}}=\bar{c}_{H H^{\prime \prime}}+\bar{c}_{H^{\prime \prime} H^{\prime}}\right)$ be the incumbent's marginal cost on the contested route $H H^{\prime}$ after code-sharing where $c_{H H}>c_{H H}$ and $\bar{c}_{H " H}>c_{H " H}$, with $c_{H H^{\prime \prime}}$ and $c_{H " H}$, as the incumbent's marginal cost on the segment $H H^{\prime \prime}$ and $H$ ' $H^{\prime}$ ' before code-sharing. So $\bar{c}_{H H^{\prime}}>c_{H H^{\prime}}$, where $c_{H H^{\prime}}=c_{H H^{\prime}}+c_{H^{\prime \prime} H^{\prime}}$. In addition, the incumbent's marginal cost on flight itineraries in its hub-and-spoke system that contain the contested segment also increases. For example, the marginal cost on route $H-H^{\prime \prime}-D$ " after code-sharing, denoted by $\bar{c}_{H D^{\prime \prime}}\left(\bar{c}_{H D^{\prime \prime}}=\bar{c}_{H H^{\prime \prime}}+c_{H^{\prime \prime} D^{\prime \prime}}\right)$, satisfies $c_{H D^{\prime \prime}}>c_{H D^{\prime \prime}}\left(c_{H D^{\prime \prime}}=c_{H H^{\prime \prime}}+c_{H H^{\prime \prime}}\right)$, where $c_{H D^{\prime \prime}}$ is the incumbent's marginal cost on route $H-H$ "'- $D$ " before code-sharing. Hence, code-sharing between firm 1 and firm 2 actually affects the marginal costs of all three firms in their respective hub-and-spoke systems.

We specify the demand and profit functions for firm 1 in its hub-and-spoke system after traditional code-sharing with firm 2 as follows:

a. The demand and profit functions between the spoke city $i$ and the hub city $H$---the segment $H i$ where $H i$ is not a code-shared segment are given by

$q_{H i}=a_{H i}-b_{H i} P_{H i}, \quad i=1, \ldots L$

and $\pi_{H i}=\left(P_{H i}-c_{H i}\right) q_{H i}, \quad i=1, \ldots L(5)$

where $c_{H i}$ is the marginal cost of firm 1 on the non-code-shared segment $\mathrm{Hi}$;

b. The demand and profit functions on the segment $\mathrm{Hm}$ where $\mathrm{Hm}$ is a traditional code-shared segment are given by $q_{H m}=a_{H m}-b_{H m} P_{H m}, \quad m=1, \ldots G, G=N-L$

and $\pi_{H m}=\left(P_{H m}-\underline{c}_{H m}\right) q_{H m}, \quad \underline{c}_{H m}<c_{H m}, \quad m=1, \ldots G, G=N-L$

where $\underline{c}_{H m}$ is the after-traditional-code-sharing marginal cost of firm 1 on the segment $H m$ and $c_{H m}$ is the before traditional-code-sharing marginal cost of firm 1 on the segment $\mathrm{Hm}$;

c. The demand and profit functions between two spoke cities $i$ and $j$ through the hub $H$ where $i-H-j$ or $j-H-i$ does not contain code-shared segments are given by $q_{i j}=a_{i j}-b_{i j} P_{i j}$,

$i=1, \ldots L ; j=1, \ldots L ; j \neq i$

and $\pi_{i j}=\left(P_{i j}-c_{i H}-c_{H j}\right) q_{i j}, \quad i=1, \ldots L ; j=1, \ldots L ; j \neq i(9)$

where $c_{i H}$ and $c_{H j}$ are the marginal costs of firm 1 on the segment $i H$ and $H j \quad$ respectively;

d.The demand and profit functions between two spoke cities $i$ and $m$ through the hub where $i-H-m$ or $m-H-i$ contains one traditional code-shared segment are given by

$q_{i m}=a_{i m}-b_{i m} P_{i m}, \quad i=1, \ldots L ; m=1, \ldots G ; G=N-L$ (10)

and $\pi_{i m}=\left(P_{i m}-c_{i H}-\underline{c}_{H m}\right) q_{i m}, \underline{c}_{H m}<c_{H m}, \quad i=1, \ldots L ; m=1, \ldots G ; G=N-L$

where $c_{i H}$ is the marginal cost of firm 1 on the segment $H i$ which is not atraditional code-shared segment while $c_{H m}$ and $\underline{c}_{H m}$ are the before and after traditional code- sharing marginal costs of firm 1 on the segment $H i$;

e. The demand and profit functions between two spoke cities $n$ and $m$ through the hub where both segments on $n-H-m$ or $m-H-n$ are code-shared segments are given by $q_{n m}=a_{n m}-b_{n m} P_{n m}, \quad m=1, \ldots G ; n=1, \ldots G ; m \neq n ; G=N-L$

and

$\pi_{n m}=\left(P_{n m}-\underline{c}_{n H}-\underline{c}_{H m}\right) q_{n m}, \underline{c}_{n H}<c_{n H}, \underline{c}_{H m}<c_{H m}$, $m=1, \ldots G ; n=1, \ldots G ; m \neq n ; G=N-L$

where $c_{n H}$ and $c_{H m}$ are the before-traditional code-sharing marginal costs of firm 1 on the segment $n \mathrm{H}$ and $\mathrm{Hm}$ while $\underline{c}_{n H}$ and $\underline{c}_{H m}$ are the after-traditional-code-sharing marginal costs of firm 1 on these two segments; The demand function on the code-shared routes with firm 2 with one segment in firm 1's hub-and-spoke system and the other one in firm 2's --- that is, the travel demand from city $H$ as the origin to city $H^{\prime}$ as the destination, is given by (take the code-shared route $H H^{\prime}$ in Figure 3.2 as example)

$q_{H H},=a_{H H},-b_{H H}, P_{H H}$, 
We base our specification of the demand function in this category on the origin and destination cities of a flight itinerary while ignoring which city is chosen as the connecting city by the code-shared alliance firms. Note that alliance firms may choose several cities as the connecting cities to set up their code-shared route agreements. It is the code-shared routes like $H H^{\prime}$ including both $H-C-H^{\prime}$ and $H-D-H^{\prime}$ that are facing the strategic responses from the market incumbent, firm 3, because firm 3 enjoys the monopoly profits before firm 1 and firm 2's codesharing. We denote the profits gained by alliance firms from code-sharing on the route $H H^{\prime}$ as $\pi_{H H}$, and they share the profits according to some proportion determined before the alliance. We assume that firm 1 gains part of the profits denoted as $\theta \pi_{H H}$, and firm 2 gains $(1-\theta) \pi_{H H}$, where $0<\theta<1$.

Therefore, firm 1's profits from its hub-and-spoke system illustrated in Figure 2.2 if code-shared with firm 2 is given by:

$$
\begin{aligned}
& \pi_{1}^{C S}=\frac{\left(a_{H A}-b_{H A} c_{H A}\right)^{2}}{\left(a_{H B}-b_{H B} c_{H B}\right)^{2}}+\frac{\left(a_{H C}-b_{H C} \underline{c}_{H C}\right)^{2}}{\left.4 a_{H D}-b_{H D} \underline{c}_{H D}\right)^{2}} \\
& --\frac{4 b_{H A}}{\begin{array}{c}
\text { Profits on routes into or out of hub } \\
\text { that are not code-shared segments }
\end{array}}---\frac{4 b_{H B}}{4 b_{H C}}--\underbrace{-1}_{\begin{array}{c}
\text { Profits on routes into or out of hub } \\
\text { that are code-shared segments }
\end{array}}-\frac{4 b_{H D}}{-}-1
\end{aligned}
$$

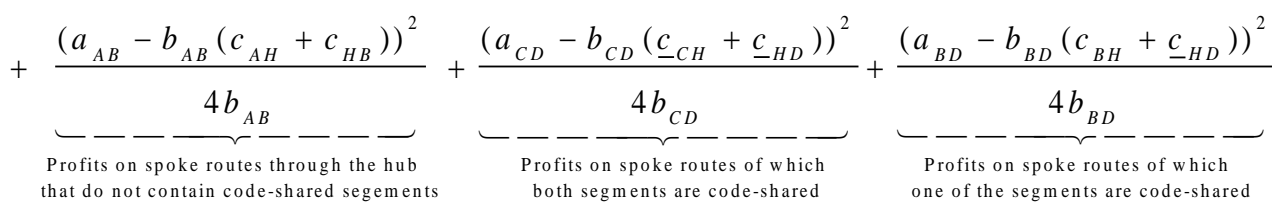

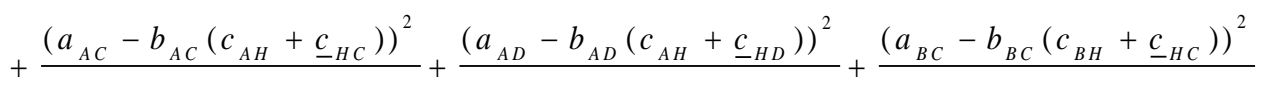

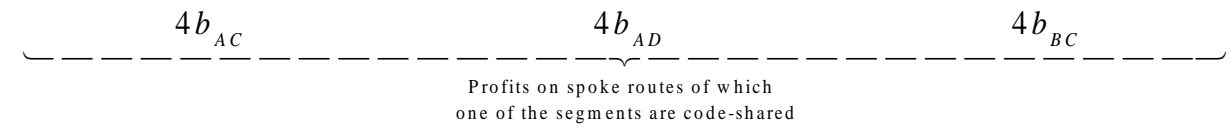

$$
\begin{aligned}
& +\underbrace{\theta \pi_{H H}}, \\
& \text { Profits gained from code } \\
& \text {-sharing on the code-shared route } \mathrm{HH}^{\prime}
\end{aligned}
$$

\subsection{Profits on the Code-Shared Route HH'}

We assume that after initial code-sharing route arrangement, whether or not staying in or exiting code-sharing on an individual code-shared route $H H^{\prime}$ ' depends on two factors: demand shocks and strategic interaction from the market incumbent on route $H^{\prime}{ }^{2}$ Based on the findings by Gayle (2008) and Du, McMullen and Kerkvliet (2008), we assume that the oligopolistic competition on the contested routes is Bertrand competition with differentiated products and that the cost structures of both the market incumbent and potential entrants (codeshared firms) are well-known to each other. Thus, firms choose prices simultaneously on the contested route $H H^{\prime}$ every time period. We also assume that there is a probability $\gamma$, that the economy is experiencing a boom period and travel demand on route $H H^{\prime}$ and the firm's whole hub-and-spoke system is high and a probability of $(1-\gamma)$ that the economy is in a recession and travel demand is low. Therefore, the entrant (assume code-shared firms are acting as one firm) competes with the market incumbent on the contested route $H H^{\prime}$ via the demand functions in the case of high demand during booms given by $q_{E}^{H}=a^{H}-b^{H} P_{E}^{H}+d^{H} P_{I}^{H}$ and $q_{I}^{H}=a^{H}-b^{H} P_{I}^{H}+d^{H} P_{E}^{H}(17)$

where $q_{E}^{H}$ and $q_{I}^{H}$ are the number of passengers carried by the entrant and incumbent respectively during booms; $P_{E}^{H}$ and $P_{I}{ }^{H}$ are the air fares charged by the entrant and incumbent respectively during booms. ${ }^{3}$

\footnotetext{
${ }^{2}$ It has been long established that the travel demand in the airline industry is quite seasonal with high demand during booms and low demand during recessions. Therefore, besides the strategic interaction from the market incumbent, we assume the demand shock also plays a role when the alliance firms decide whether to stay code-shared or exit code-sharing on an individual route at a specific time period.

${ }^{3}$ Through the paper, the superscripts $\mathrm{H}$ and $\mathrm{L}$ means high and low demand. The subscript $\mathrm{H}$ means the hub city and the subscripts $E$ and I mean the entrant and incumbent respectively.
} 
Let $c_{E}^{H}$ and $c_{I}^{H}$ be the marginal costs of the entrant and incumbent respectively on route $H H^{\prime}$ ' during booms where $c_{E}^{H}=\frac{\underline{c}_{H-C-H^{\prime}}^{H}+\underline{c}_{H-D-H^{\prime}}^{H}}{2}$ and $c_{I}^{H}=\bar{c}_{H H^{\prime \prime}}+\bar{c}_{H^{\prime \prime} H^{\prime}}$. In accordance to the notation of marginal costs defined on spoke cities earlier in the paper, $\underline{c}_{H-C-H}^{H}=\underline{c}_{H C}^{H}+\underline{c}_{C H}^{H}$, and $\underline{c}_{H-D-H}^{H}, \underline{c}_{H D}^{H}+\underline{c}_{D H}^{H}$. Let $c_{E}^{L}$ and $c_{I}^{L}$ be the marginal costs of the entrant and incumbent respectively on route $H H^{\prime}$ ' during recessions. Then due to the economies of traffic density, low demand during recessions will lead to higher marginal cost: $c_{E}^{H}<c_{E}^{L}$ and $c_{I}^{H}<c_{I}^{L}$. By the same token, the marginal cost of firm 1 during booms on the routes that contain code-shared segments after alliances will be lower than the marginal cost during recessions. For example, the after-code-sharing marginal cost of firm 1 on the code-shared segment $H C$ during booms, denoted as $\underline{c}_{H C}^{H}$, satisfies $\underline{c}_{H C}^{H} \underline{c}_{H C}^{L}$, where $\underline{c}_{H C}^{L}$ the after-codesharing marginal cost is during recessions. Then the profit functions of the entrant and incumbent are given by $\pi_{E}^{H}=\left(P_{E}^{H}-c_{E}^{H}\right) q_{E}^{H}$ (18)and $\pi_{I}^{H}=\left(P_{I}^{H}-c_{I}^{H}\right) q_{I}^{H}$

A simultaneous solution to equation (16) and (17) gives us the equilibrium prices of the entrant and incumbent respectively as follows:

$$
\begin{aligned}
& P_{E}^{H}=\frac{a^{H} d^{H}+2 a^{H} b^{H}+2\left(b^{H}\right)^{2} c_{E}^{H}+b^{H} d^{H} c_{I}^{H}}{\left(d^{H}\right)^{2}-4\left(b^{H}\right)^{2}}(20) \\
& P_{I}^{H}=\frac{a^{H} d^{H}+2 a^{H} b^{H}+b^{H}\left(4 b^{H}-d^{H}\right) c_{E}^{H}+2 b^{H}\left(d^{H}-b^{H}\right) c_{I}^{H}}{\left(d^{H}\right)^{2}-4\left(b^{H}\right)^{2}}
\end{aligned}
$$

Substitute $P_{E}^{H}$ in equation (20) into (18), we will get $\pi_{E}^{H}\left(\pi_{H{ }^{H}}^{H}\right)$.

The entrant's (firm 1) profits from its flight system during booms are given by

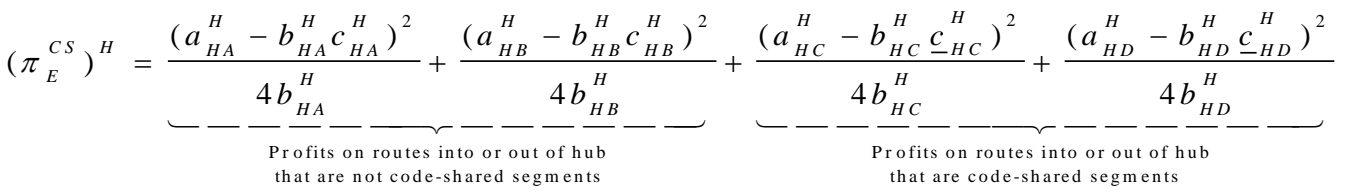

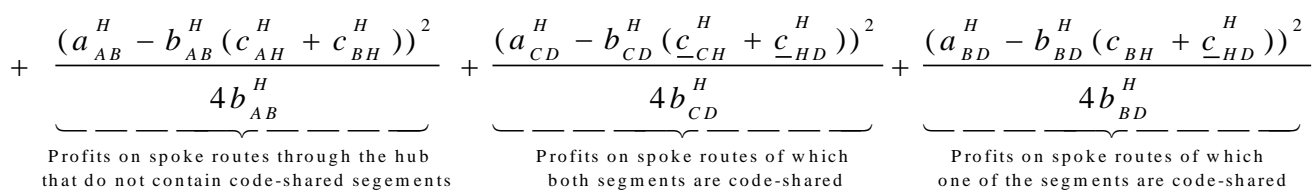

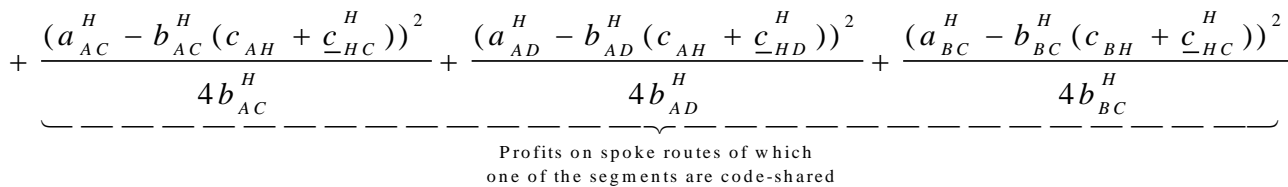

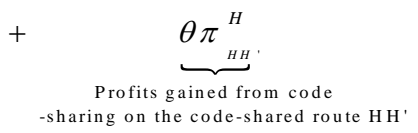

Accordingly, we can write out firm 1's profits from its whole flight system after code-sharing during recessions as $\left(\pi_{E}^{C S}\right)^{L}$. So the expected profits of firm 1 before and after code-sharing are given by $E \pi_{E}^{N C S}=\gamma\left(\pi_{E}^{N C S}\right)^{H}+(1-\gamma)\left(\pi_{E}^{N C S}\right)^{L}$ and $E \pi_{E}^{C S}=\gamma\left(\pi_{E}^{C S}\right)^{H}+(1-\gamma)\left(\pi_{E}^{C S}\right)^{L}$ respectively. If we assume that the entrant and incumbent are playing super games on a finite time horizon from $t=1, \ldots \mathrm{T}$, then the equilibrium price and profits obtained in every time period are the equilibrium price and profits for the whole time horizon.

Therefore, firm 1 (firm 2) will enter code-sharing alliances if $\frac{1-\delta^{T+1}}{1-\delta} E \pi_{E}^{C S}-F>\frac{1-\delta^{T+1}}{1-\delta} E \pi_{E}^{N C S}$

where $\delta$ is the one period inter-temporal discount factor common to both players and $F$ stands for the sunk cost in the event of code-sharing, which reflects any non-recoverable start-up investment cost associated with entering 
code-sharing alliances such as the purchase of airport gates, advertisement, leasing payment or equity ownership investment. Define

$$
X=\frac{1-\delta^{T+1}}{1-\delta} E \pi_{E}^{C S}-F-\frac{1-\delta^{T+1}}{1-\delta} E \pi_{E}^{N C S}
$$

Hence, if $X>0$, then firm 1 (firm 2) enters code-sharing; otherwise, they operate their own hub-and-spoke system without alliances.

After initial start-up investment costs in entering code-sharing, the entrant (firm 1) will choose to stay code-shared on the contested route $H H^{\prime}$ if $\frac{1-\delta^{T+1}}{1-\delta}\left(E \pi_{E}^{C S}\right)_{w / t H H^{\prime} \text { code-shared }}>\frac{1-\delta^{T+1}}{1-\delta}\left(E \pi_{E}^{C S}\right)_{w / o H H^{\prime} \text { code-shared }}-\delta^{t-1} C_{e x i t-H H^{\prime}}$

(25)where $\left(E \pi_{E}^{C S}\right)_{w / O H H^{\prime} \text { code-shared }}$ is the expected profits from firm 1's hub-and-spoke system with once-codeshared route $H H^{\prime}$ ' dropped while other code-shared routes still exist in the system and $C_{e x i t-H H}$, is the exit cost of dropping route $H H^{\prime}$ from code-sharing. Define

$$
Y=\frac{1-\delta^{T+1}}{1-\delta}\left(E \pi_{E}^{C S}\right)_{w / t H H^{\prime} \text { code-shared }}-\left(\frac{1-\delta^{T+1}}{1-\delta}\left(E \pi_{E}^{C S}\right)_{w / o H H^{\prime} \text { code-shared }}-\delta^{t-1} C_{e x i t-H H^{\prime}}\right)
$$

Hence, if $Y>0$, then firm 1 (firm 2) will choose to stay code-shared on route $H H^{\prime}$; otherwise, they will drop $H H^{\prime}$ from code-sharing while keeping other code-shared routes in their hub-and-spoke systems.

The following represents all possible equilibrium outcomes:

E1: No code-sharing if $X \leq 0$;

E2: Enter code-sharing and stay if $X>0$ and $Y \geq 0$;

E3: Enter code-sharing and exit if $X>0$ and $Y<0$.

\section{Conclusions}

Code sharing has been an important and popular alliance form among air carriers. In the paper, we derive three Nash equilibriums as economies of traffic density and price elasticity of demand vary during the business cycles and therefore strategic decisions of traditional code-sharing differ as market conditions change. Extension of the current model could take virtual code-sharing and welfare analysis of different kinds of code-sharing into consideration.

\section{Acknowledgements}

This research was partially funded by College Research Grant of Beijing Normal University-HongKong Baptist University United International College (BNU-HKBU UIC) under financial codeR201410. The author wishes to thank participants in paper sessions at the $19^{\text {th }}$ Air Transport Research Society (ATRS) World Conference for helpful comments and suggestions.

\section{Table 1.1 Changes in the Number of Code-shared (CS) Routes}

\begin{tabular}{l|l|l|l|l|l}
\hline Quarter $^{4}$ & CS Routes & New CS Entries & New CS Entries \% & New CS Exits & New CS Exits \% \\
\hline 1998Q1 & 731 & N/A & N/A & N/A & N/A \\
1998Q2 & 765 & 351 & $45.9 \%$ & 317 & $43.4 \%$ \\
1998Q3 & 635 & 246 & $38.7 \%$ & 376 & $49.2 \%$
\end{tabular}

\footnotetext{
${ }^{4}$ Information on code-shared routes between Continental and America West is available from Bureau of Transportation Statistics (US Department of Transportation) only from 1998 because of reporting requirements adopted by the Congress in 1998.

${ }^{5}$ A route is defined as a new code-shared entry if carriers did not code-share in the previous period but code-share at the current period; A route is defined as new code-shared exit if carriers code-shared in the previous period but do not code-share at the current period.

${ }^{6}$ New code-shared entry percentage is calculated as new code-shared entries at the current period divided by code-shared routes at the current period.

${ }^{7} \mathrm{New}$ code-shared exit percentage is calculated as new code-shared exits from the previous period divided by code-shared routes in the previous period.
} 


\begin{tabular}{l|l|l|l|l|l} 
1998Q4 & 620 & 282 & $45.5 \%$ & 297 & $46.8 \%$ \\
1999Q1 & 823 & 446 & $54.2 \%$ & 243 & $39.2 \%$ \\
1999Q2 & 627 & 251 & $40.0 \%$ & 447 & $54.3 \%$ \\
1999Q3 & 803 & 396 & $49.3 \%$ & 220 & $35.1 \%$ \\
1999Q4 & 889 & 350 & $39.4 \%$ & 264 & $32.9 \%$ \\
2000Q1 & 760 & 217 & $28.6 \%$ & 346 & $38.9 \%$ \\
2000Q2 & 770 & 272 & $35.3 \%$ & 262 & $34.5 \%$ \\
2000Q3 & 515 & 137 & $26.6 \%$ & 392 & $50.9 \%$ \\
2000Q4 & 503 & 193 & $38.4 \%$ & 205 & $39.8 \%$ \\
2001Q1 & 425 & 140 & $32.9 \%$ & 218 & $43.3 \%$ \\
2001Q2 & 331 & 139 & $42.0 \%$ & 233 & $54.8 \%$ \\
2001Q3 & 305 & 140 & $45.9 \%$ & 166 & $50.2 \%$ \\
2001Q4 & 358 & 182 & $50.8 \%$ & 129 & $42.3 \%$ \\
2002Q1 & 277 & 93 & $33.6 \%$ & 174 & $48.6 \%$ \\
2002Q2 & 208 & 71 & $34.1 \%$ & 140 & $50.5 \%$ \\
2002Q3 & 28 & 17 & $60.7 \%$ & 197 & $94.7 \%$ \\
2002Q4 & 14 & 13 & $92.9 \%$ & 27 & $96.4 \%$ \\
\hline
\end{tabular}

Table 1.2 Time of Code-sharing for Different Code-shared Routes

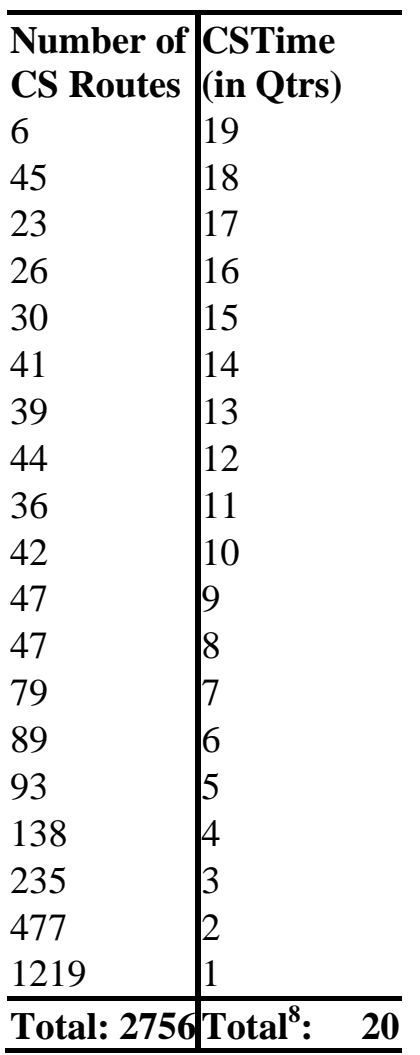

\footnotetext{
${ }^{8}$ The whole period of code sharing time is only calculated from the first quarter of 1998 due to the data unavailability before
} 1998 from Bureau of Transportation Statistics U.S. Department of Transportation. 
Figure 2.1 Firm 1's Airline Hub-and-spoke System

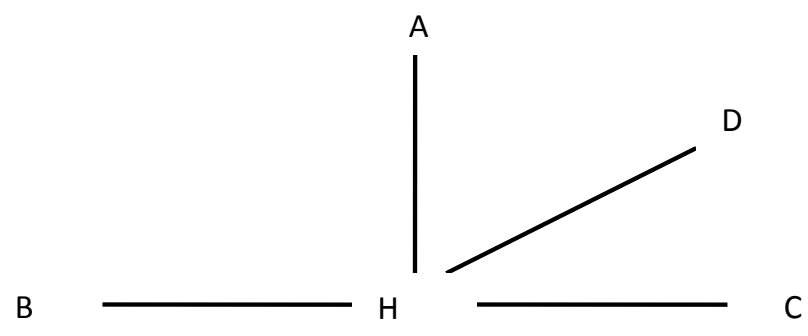

Figure 2.2 Code-sharing Alliances under Airlines' Hub-and-spoke Flight Systems

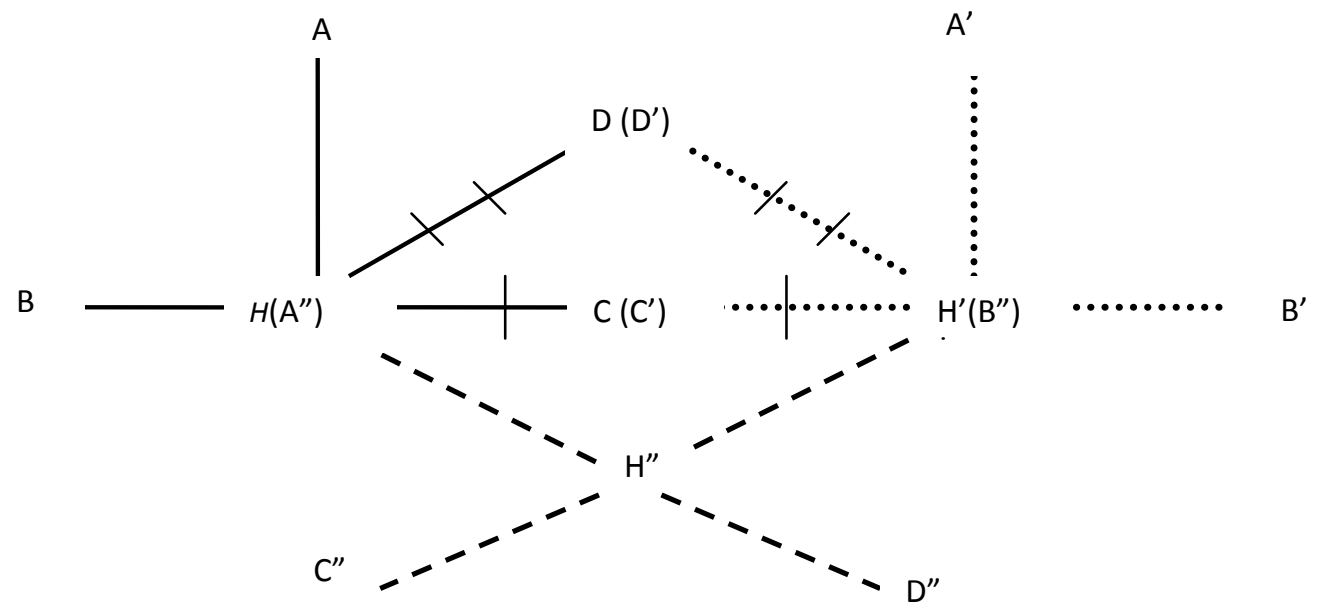

\section{Reference}

Armantier, O. and Richard, O. (2005a), "Evidence on Pricing from the Continental Airlines and Northwest Airlines Code-Share Agreement", D. Lee (eds.) Advances in Airline Economics V1, 2006. Elsevier Publisher;

------(2005b), "Domestic Airline Alliances and Consumer Welfare”, Working papers, University of Montreal, Canada;

Bamberger, G.E., Carlton, D.W. and Neumann, L.R. (2004), “An Empirical Investigation of the Competitive Effects of Domestic Airline Alliances", Journal of Law and Economics, V XLVII, 195-222;

Bilotkach, V. (2007), "Complementary versus Semi-complementary Airline Partnerships", Transportation Research Part B, V41, 381-393;

Brueckner, J.K. (2001), "The Economics of International Code-sharing: an Analysis of Airline Alliances," International Journal of Industrial Organization, V19, 1475-1498;

-----(2003), "International Airfares in the Age of Alliances: The Effects to Code-sharing and Antitrust Immunity", Review of Economic Statistics, V85, 105-118;

Brueckner, J.K. and Whalen, W.T. (October 2000), "The Price Effect of International Airline Alliances", Journal of Law and Economics, V XLIII, 503-544; 
Chua, C.L., Kew, H and Yong, J (2005), "Airline Code-sharing Alliances and Costs: Imposing Concavity on Translog Cost Function Estimation", Review of Industrial Organization V26, 461-487;

Du, Y., McMullen, B. S. and Kerkvliet, J. (2008), "The Economic Impact of the ATA/Southwest Airlines codeshare agreement", Research in Transportation Economics, Elsevier,V24(1), 51-60;

Du, Y., McMullen, B. S. (2015), "Is the Decision to Code-Share a Route Different for Virtual than for Traditional Code-Share Arrangements?" Journal of Transportation Research Forum, V54(1), 43-58.

Gayle, P.G. (2008), "Airline Code-share Alliances and Their Competitive Effects", Journal of Law and Economics, V51(4), 743-766;

Hassin, O. and Shy, O. (2004), "Code-sharing Agreements and Interconnections in Markets for International Flights", Review of International Economics, V12(3), 337-352;

Ito, H., and Lee, D. (2007), "Domestic Code Sharing, Alliances, and Airfares in the U.S. Airline Industry", Journal of Law and Economics, V50, 355-380;

Ito, H. and Lee, D. (2005), "Assessing the Impact of September 11 On U.S. Airline Demand", Journal of Economics and Business, 57, 75-95;

McMullen, B.S. and Du, Y. (2012), "Determinants of Successful Code-sharing: A Case Study of Continental and America West Airlines Alliances - A Discrete Longitudinal Analysis", J. Peoples (eds.) Advances in Airline Economics V3 Pricing Behavior and Non-Price Characteristics in the Airline Industry, 2012. Emerald Publisher;

Oum, T.H., Park, J.H. and Zhang, Y.(1996), "The Effects of Airline Code-sharing Agreements on Firm Conduct and International Air Fares", Journal of Transport Economics and Policy, V30(2), 187-202;

Oum, T.H., Zhang, A., and Zhang, Y. (1995), “Airline Network Rivalry”, Canadian Journal of Economics, V28, 836-857;

Park, J.H. (1997), "The Effects of Airline Alliances on Markets and Economic Welfare", Transportation Research Part E: Logistics and Transportation Review, V33(3), 181-195;

Park, J.H., Park, N.K. and Zhang, A. (2003), "The Impact of International Alliances on Rival Firm Value: A Study of the British Airways US Air Alliance", Transportation Research Part E: Logistics and Transportation Review, V39(1), 1-18;

Park, J.H. and Zhang, A. (2000), "An Empirical Analysis of Global Airline Alliances: Cases in North Atlantic Markets", Review of Industrial Organization, V16: 367-383;

Park, J.H., Zhang, A. and Zhang, Y.(2001), "Analytical Models of International Alliances in the Airline Industry", Transportation Research Part B: Methodological, V35(9), 865-886;

Sinclair, R.A. (1993), An Empirical Model of Entry and Exit in Airline Markets, PhD Dissertation, University of Pittsburgh;

---(1995), “An Empirical Model of Entry and Exit in Airline Markets”, Review of Industrial Organization, 10(5), $541-557$ 